\title{
NEW EPOXY WITH SELF-REPAIRING PROPERTIES OF ENVIRONMENTAL-FRIENDLY BUILDING STRUCTURE ADHESIVES
}

\begin{abstract}
With the rapid increase in newly constructed buildings, the number of old buildings that need reinforcement and repair also increases due to aging, accidental damage, or modernization refurbishment. Likewise, the demand of the building adhesive keeps growing with the expansion of its application scope. However, because of the recognition of many demerits of the existing epoxy building adhesives (e.g., low bonding strength, high frangibility, and low elasticity modulus), the need for a new environment-friendly building structure adhesive has been growing steadily. In this paper, the potential of nano-scaled rubber (VP-501: diameter of $\sim 70 \mathrm{~nm}$ ) was investigated with respect to its capacity to enhance the capacity of the epoxy resin with respect to the static tensile, fracture toughness, and dynamic mechanical properties. Further, its effects on the thermal stability and glass-transition temperature change were also examined with the content of toughening agent. Our discussion was extended further to describe the mechanism under which the toughness and heat resistance of the modified epoxy resin are improved.
\end{abstract}

Keywords: building adhesive modified epoxy resin, environment

\section{Introduction}

In 1946, since the bisphenol an epoxy resin has been introduced, epoxy resin adhesive had entered a rapid development phase [1]. Over the past 50 years, hundreds of epoxy resin products have been developed, undergoing a tremendous change in the structure of product $[2,3]$. The use of epoxy resin has basically covered all industries, as its annual growth rate of consumption is kept at a level of more than $10 \%$ [4].

Building structure adhesive system includes several types such as epoxy resin and modified epoxy resin, acrylic resin, unsaturated polyester resin [5], and polyurethane resin. Since the epoxy resin has many properties that could not be matched by any other thermoset resin, in addition to advantages of the general polymers [6], it has been more widely used as a primary adhesive [7,8]. Currently, the building structure adhesive has been applied in various engineering construction projects such as housing reinforcement, highway and bridge construction, anchoring and extension, and decoration and sealing [9]. The use of epoxy resin building structure adhesive is made dominantly in many different fields such as steel plate bonding reinforcement, highway pavement rapid repair technology

\footnotetext{
${ }^{1}$ School of Civil Engineering, Architecture and Environment, Xihua University, Chengdu 610039 China

${ }^{2}$ Chengdu Textile College, Chengdu, 610039, China, email: 87660164@qq.com

${ }^{3}$ College of Tourism and Service Management, Nankai University, Tianjin 300071, China, email: chateau.frank@gmail.com

*Corresponding author:0720090008@mail.xhu.edu.cn
} 
[10], carbon fiber sheet reinforcement, and reinforcement bar implantation technology. The modern construction adhesive has been developing towards directions of high strength, economy, easy use and environmental compatibility [12], beyond the field of bonding. As a new type of functional composite material, the building adhesive could provide more and better options for civil engineering construction projects, and it has become a shining star in the field of civil engineering materials [13].

In the early 1950s, epoxy resin had been already used in civil engineering construction widely. For example, the epoxy resin adhesive was used for the first time to quickly repair road pavement in New Jersey, US. By the 1960s, with the development of polymer synthetic materials, the building adhesive had been used in projects such as highway, highway bridge and airport runway construction, as well as the hydraulic engineering and military installation reinforcement projects, in some developed countries. In the 1970s, various excellent construction adhesives emerged successively, and their application scope was expanded into more fields, such as bonding of on-site construction components and anchoring of steel bars, etc. [14, 15]. When the Maracaibo Lake Bridge was built in Venezuela, the building adhesive had been applied onto the base of bridge pier, and the bridge had been in good service condition for many years. In 1971, after a major earthquake in San Fernando, California, the Municipal Building of $137 \mathrm{~m}$ in height and a ten-storey hospital building were repaired and reinforced with the building adhesive, and total 7.5 Mg (tonnes) of adhesive were used. In 1983, the British University of Sefel successfully strengthened a bridge with the building adhesive, achieving an increase in the loading limit of the bridge from 110 to $500 \mathrm{Mg}$. In the 1990s, as the further research work has been conducted in various countries, many dedicated adhesive companies such as Sika (Swiss) and 3M (US) have developed a variety of adhesive products for different situations, with the superior performance. Continuous increase in the application amount of the building adhesive makes it more and more important for the development of the whole adhesive industry [16].

The development of bi-component epoxy adhesive has reached a certain level with respect to the scale in China in the late 1990s. Currently, the major differences between our country and the advanced foreign countries in the adhesive industry could be summarized as below. (1) The variety of adhesive products are less in China. There are several types of adhesive rarely found in China, such as the adhesive with high temperature resistance, adhesive with high peeling strength and adhesive that could solidify rapidly at room temperature etc. (2) The quantity of adhesive products is small. Only dozens of room temperature solidifying adhesive products could be acquired in the market. (3) The performance of adhesive products is poor. There is almost no adhesive product that could reach the performance criteria below at the room temperature: the shear strength $>30 \mathrm{MPa}$, and the peeling strength > $3.0 \mathrm{kN} / \mathrm{m}$. (4) The development prospect is not optimistic [17]. The amount of scientific research funding is too small; and there are not sufficient fine chemical raw materials that needed for synthesizing new epoxy resin and curing agent, etc. Additionally, after accession into the World Trade Organization, a lot of foreign commodities have been flowing into China, which is also considered as one of the factors that restrict the development of adhesive field in our country [18]. 


\section{Tensile properties}

Review the relevant literature, combined with the development status of infrastructure construction and emission reduction technology in Guangdong Province, China, and we choose to get each subsystem's indicators. The load-displacement curve of the system before and after modification is shown in Figure 1. It could be seen that as the content of VP-501 increases, the breaking load increases significantly, and the elongation at break of the composite material also shows an increasing trend. The breaking pattern of the whole system gradually changes from the brittle fracture to the yield ductile fracture.

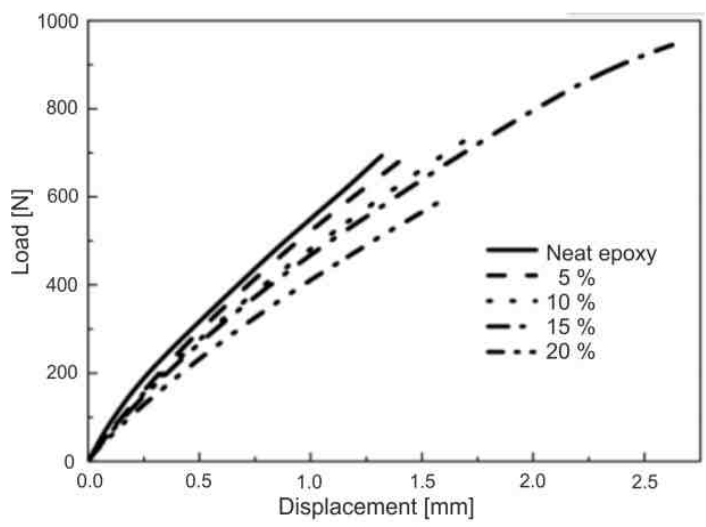

Fig. 1. Load - displacement curve of VP-501 modified epoxy system under different content

Figure 2 shows the trend in which the tensile strength of the modified epoxy system changes as the content of nano-rubber particles changes. The tensile strength of the modified epoxy system shows a trend to increase first and decrease later as the content of VP-501 increases, and reaches the peak when the content of nano-rubber reaches $15 \%$; and that the tensile strength increases from 46.25 to $61.34 \mathrm{MPa}$, increased by a percentage of $32.63 \%$ compared with the pure epoxy resin. Subsequently, with the addition of nano-rubber, the tensile strength of the system begins to decline, indicating that excess nano-rubber will agglomerate and thus impair the toughening effect. Generally, addition of rubber into the epoxy resin will always reduce its tensile strength at room temperature. However, addition of VP-501 nano-rubber into the epoxy resin does lead to a significant increase in the tensile strength of the system rather than decrease. Since the surface of nano-rubber contains a large amount of active groups, such as carboxyl and hydroxyl, when it is added into the epoxy resin, the active groups on the surface of rubber particles will react with the epoxy groups to form ester bonds, resulting in a highly cross-linked network structure, which contributes to formation of a stable and tight interface between the toughening particles and the matrix. Additionally, the nano-rubber particles could not only keep their rubber elasticity, but also realize an even dispersion in the epoxy resin matrix due to the gradient cross-linked structure formed by the nano-rubber particles. When the composite material is subjected to an applied load, the stress is concentrated on the nano-rubber particles first, and the strength of interface between the nano-rubber and the epoxy resin is high due to the presence of chemical bonds. Therefore, it is considered that the addition of nano-rubber could result in a mitigation of stress concentration, leading 
to an increase in the tensile strength of the modified system. From the view of microstructure change, addition of nano-rubber increases the cross-linking density of the epoxy resin system, and the movement of the polymer chain is limited. When it is subjected to an external stress, the tensile strength of the composite material will increase as the cross-linking density increases.

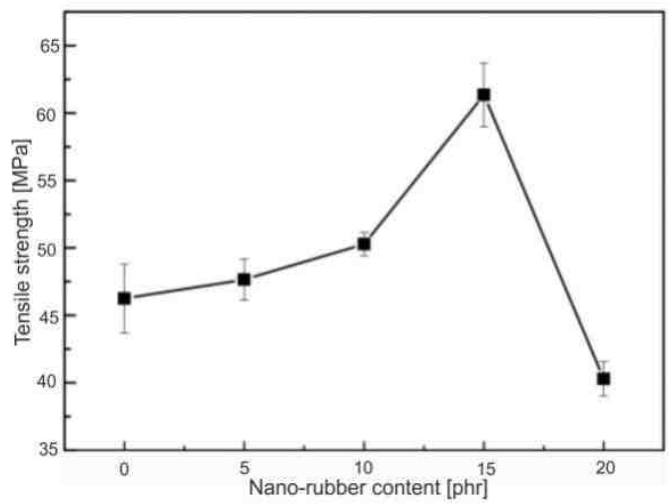

Fig. 2. Effect of VP-501 addition on tensile strength of epoxy resin

When an object is subjected to an external force, it will undergo the elastic deformation if the elastic limit of the object is not exceeded. When the elastic deformation occurs, an internal stress will be generated inside the material, to restore the shape of the object. Elastic modulus is a physical parameter that could reflect the ability of a material to resist deformation, which is used as one of the bases for selecting materials in engineering.

Figure 3 shows that the tensile modulus of the system shows a decreasing trend with the increase of VP-501 content, which could be explained by the fact that addition of elastic particles of carboxyl-terminated nitrile butadiene rubber has reduced the rigidity of the system, compared with the pure epoxy resin, because the rigidity of the nano-particles is lower than that of the matrix material.

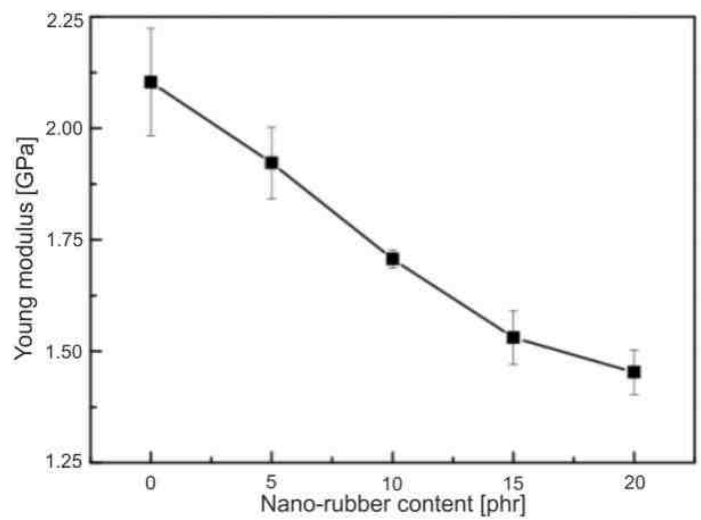

Fig. 3. Effect of VP-501 content on elastic modulus of epoxy resin system 
Figure 4 shows a trend in which the failure strain of the epoxy resin composite changes with the content of nano-rubber. It could be seen that the failure strain at room temperature increases with the increase of VP-501 content. When its content is $15 \%$, the strain reaches the peak point, from 2.2 to $4.33 \%$, and then decreases slightly. Addition of elastic nano-particles will reduce the rigidity of the epoxy cross-linked network and enhance the mobility of the molecular chain, leading to an increase in the failure strain of the system at room temperature. This result is in coincide with the trend of tensile strength with the increase of VP-501 addition in Figure 2.

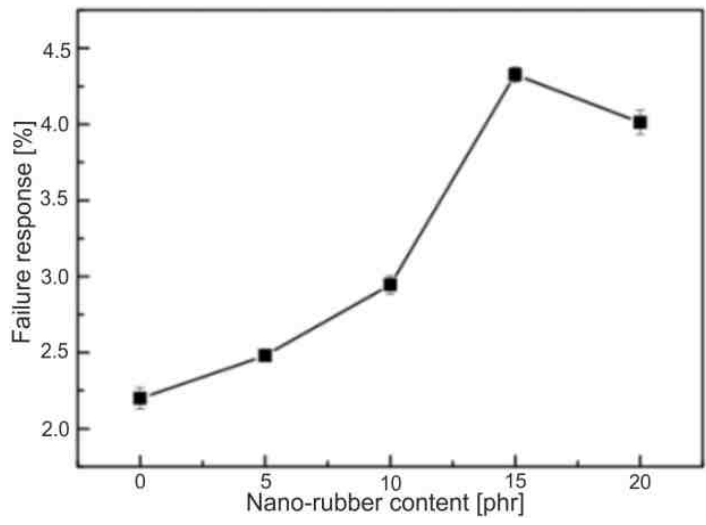

Fig. 4. Effects of strain on the VP-501 content of the epoxy resin system failure

In summary of all tensile mechanical properties above, Table 1 below has completely shown the corresponding data.

Table 1

Tensile mechanical properties of the system

\begin{tabular}{|c|c|c|c|}
\hline $\begin{array}{c}\text { Nano-rubber content } \\
\text { [phr*] }\end{array}$ & $\begin{array}{c}\text { Tensile strength } \\
{[\mathbf{M P a}]}\end{array}$ & $\begin{array}{c}\text { Young's modulus } \\
{[\mathbf{G P a}]}\end{array}$ & $\begin{array}{c}\text { Failure response } \\
{[\%]}\end{array}$ \\
\hline Pure epoxy resin & $46.25 \pm 2.54$ & $2.10 \pm 0.12$ & $2.20 \pm 0.07$ \\
\hline 5 & $47.66 \pm 1.53$ & $1.92 \pm 0.08$ & $2.48 \pm 0.04$ \\
\hline 10 & $50.28 \pm 0.86$ & $1.71 \pm 0.02$ & $2.95 \pm 0.06$ \\
\hline 15 & $61.34 \pm 2.35$ & $1.53 \pm 0.06$ & $4.33 \pm 0.05$ \\
\hline 20 & $40.30 \pm 1.22$ & $1.45 \pm 0.05$ & $4.01 \pm 0.08$ \\
\hline
\end{tabular}

$\mathrm{phr}=$ parts per hundreds of rubber

\section{Fracture toughness}

Figure 5 shows how the fracture toughness of VP-501 modified epoxy resin changes with the content of VP-501. It could be seen that when the nano-rubber is added, the fracture toughness of the epoxy resin material increases as the content of VP-501 increases, and the addition of nano-rubber has exhibited a good toughening effect. When the content of nano-rubber is $15 \%$, the fracture strength factor of the composite material will increase from 1.12 to $3.01 \mathrm{MPa} \cdot \mathrm{m}^{1 / 2}$ by a percentage of $168.7 \%$.

The nano-rubber could accomplish nano-scale dispersion in the epoxy resin due to its small particle size, so the interface between the two phases is large. The phase interface of 
the epoxy resin modified by VP-501 elastic nano-rubber with a particle size of $70 \mathrm{~nm}$ is enlarged more than 100 times, compared with the epoxy resin modified by liquid-terminated carboxylated nitrile butadiene rubber with a particle size of 1,000 nm. The active groups at the VP-501 nano-particle interface form more chemical bonds with the epoxy groups in the epoxy resin, and the -CN groups at the VP-501 nano-particle interface form more hydrogen bonds with the $-\mathrm{OH}$ groups in the epoxy resin. The adhesion between the two phase interfaces is improved due to the enlargement of the interface between two phases and the significant increase of hydrogen bonds and chemical bonds, leading to an effect on the motions of molecules and polymer chains at the interface between two phases. Therefore, the interfacial properties and macroscopic mechanical properties are improved in the modified epoxy resin, thus causing a significant increase in the fracture toughness of the modified epoxy resin.

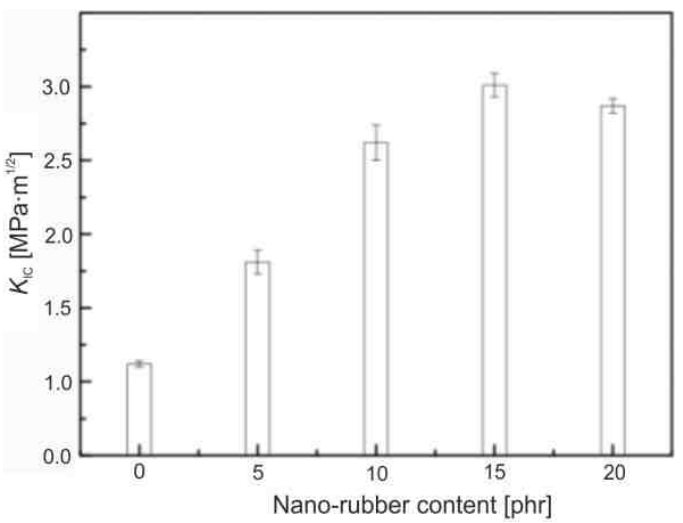

Fig. 5. Effect of VP-501 content on fracture toughness of epoxy resin

Effect of VP-501 content on fracture toughness of epoxy resin

Table 2

\begin{tabular}{|c|c|}
\hline $\begin{array}{c}\text { Nano-rubber content } \\
{[\mathbf{p h r}]}\end{array}$ & $\begin{array}{c}\boldsymbol{K}_{\mathbf{I C}} \\
{\left[\mathbf{M P a} \cdot \mathbf{m}^{\mathbf{1} / 2}\right]}\end{array}$ \\
\hline Pure epoxy resin & $1.12 \pm 0.12$ \\
\hline 5 & $1.81 \pm 0.08$ \\
\hline 1 & $2.62 \pm 0.12$ \\
\hline 15 & $3.01 \pm 0.08$ \\
\hline 20 & $2.87 \pm 0.05$ \\
\hline
\end{tabular}

As it is indicated in the traditional theory on toughening the epoxy resin with rubber, the diameter of rubber particles in the dispersion phase has an optimum range, and if the diameter of rubber particle is too small, the toughening effect of the epoxy resin will be impaired. McGarry et al. has found that when the diameter of CTBN particle is less than $100 \mathrm{~nm}$, it will have no toughening effect on the epoxy resin. But when we use the elastic nano-rubber with a particle diameter of only $70 \mathrm{~nm}$, the toughening effect is significantly better than that of the CTBN with a large particle diameter. Based on the results of observation on the fracture surface of elastic nano-particle toughened epoxy resin by a scanning electron microscopy, it could be seen that the brittle fracture appears near the 
crack tip in the pure epoxy resin, and the fracture surface is very smooth. After the nano-rubber VP-501 is added, the ductile fracture appears near the crack tip, which is reflected by the river-shaped or beach-shaped extension of cracks. Currently, following statements on mechanism under which the rubber improves the toughness of epoxy resins have been accepted widely. (1) Epoxy resin matrix shear zones between adjacent rubber particles could form local shearing yield; (2) holes or plastic defects occurs in the epoxy matrix, which are formed through the debonding and cavitation of the rubber particles; and (3) rubber particles at crack tip could generate a bridging effect. In all these statements on the toughening mechanism, the particle diameter of rubber is always an important parameter. According to a new theory on interaction between rubber particles and plastic zone, rubber particles smaller than the plastic zone of the pure epoxy resin could interact with the plastic zone at tip to generate the cavitation effect and contribute to the occurrence of shearing yield, resulting in an excellent toughening effect. Due to the small particle diameter of the elastic nano-particles we used, the epoxy matrix could produce a larger plastic flow and plastic deformation zone when the epoxy resin is subjected to an external load, therefore, the elastic nano-particles could greatly improve the toughness of epoxy resin.

a)

c)
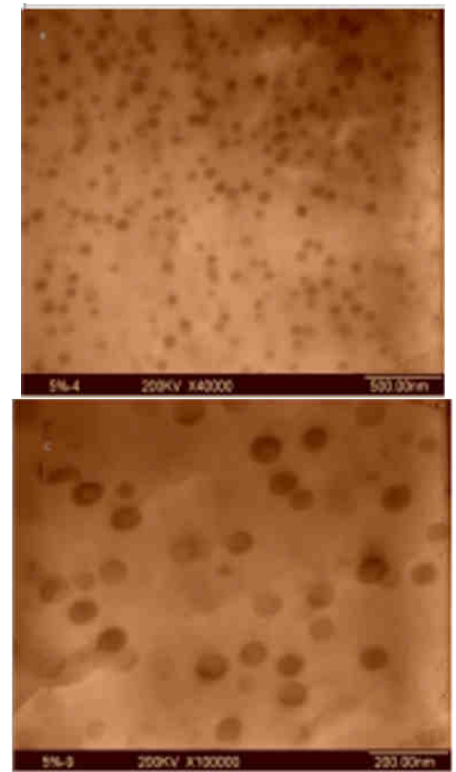

b)

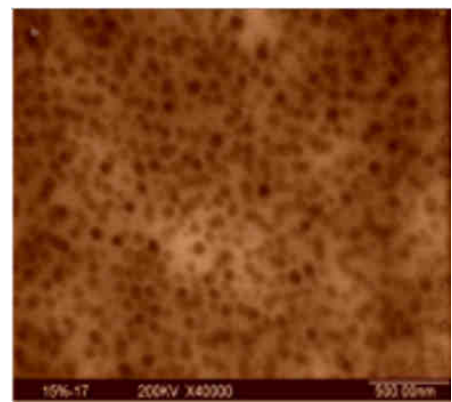

d)

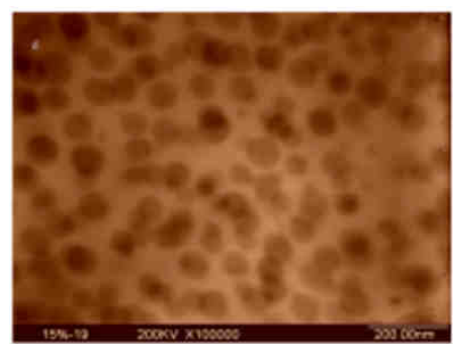

Fig. 6. TEM photograph of nano-phase modified epoxy: resin a), c): content of $5 \%$; b), d) content of $15 \%$

During the radiation vulcanization of nano-rubber particles, unsaturated double bonds of large molecules on the surface of rubber particles are more likely to undergo the cross-linking reaction, leading to a higher cross-linking degree. On the contrary, the rubber molecules inside the rubber particles are less likely to undergo the cross-linking reaction, thus leading to a lower cross-linking degree. Therefore, the microstructure of elastic nano-particles should adopt a special "gradient cross-linked structure", which could not 
only retain the elasticity of the rubber, but also avoid the agglomeration of the rubber particles, making them easier to realize the nano-scale dispersion in the resin matrix.

Figure 6 shows the transmission electron microscope images of modified epoxy resin with different nano-phase contents. It could be seen that in the epoxy resin matrix, the spherical nano-rubber particles are well dispersed in the form of individual particles, and the size of nano-rubber particles is still kept at about $70 \mathrm{~nm}$. Such a good dispersion of the nano-rubber particles has further verified that the cross-linking degree on rubber particle surface is higher than that of the special gradient cross-linked structure inside the particle. When the composite material is subjected to an external stress, the uniformly dispersed nano-rubber could generate a passivation effect and bridge the brittle solidified parts of epoxy resin, to improve the toughness of the epoxy resin matrix, achieving a good modification and toughening effect.

\section{Dynamic mechanical properties}

Dynamic Mechanical Analysis (DMA) is a thermo-mechanical analysis technology, which is used to measure the dynamic modulus, mechanical loss and temperature correlation of materials under vibration load at the programmed increasing temperature conditions. At present, DMA is widely used in the studies of polymer materials, and it has several scanning modes such as sample temperature, frequency and deformation. As properties of a material (such as modulus, mechanical loss $\tan \delta$ and the viscosity) change with temperature, frequency or time, a series of scanning curves could be shown, and basic parameters of the material (such as the glass-transition temperature $T_{\mathrm{g}}$ in the curve $\tan \delta$ ) could be determined. Additionally, the detailed information on the heat resistance and toughness of the material could also be gained.

Figure 7 shows the relationship between storage modulus and temperature of the epoxy resin composite when different contents of VP-501 are added. It could be seen from the Figure that the initial storage modulus $\left(50^{\circ} \mathrm{C}\right)$ of nano-composite shows a trend to increase first and decrease later after the nano-rubber is added, and that when the content is $15 \%$, the initial storage modulus increases from $1.375 \cdot 10^{9}$ to $1.764 \cdot 10^{9} \mathrm{MPa}$, increased by a percentage of $28.3 \%$.

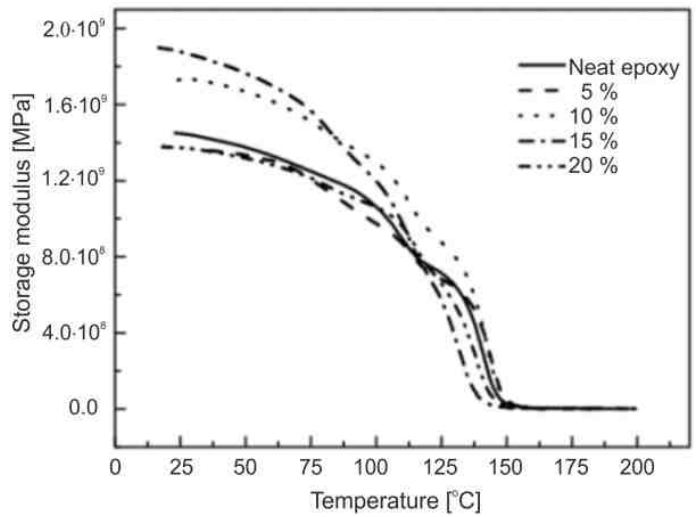

Fig. 7. Effect of nano-rubber content on storage modulus curve of composite material 


\section{Conclusion}

With the development of adhesive products, studies on building structure adhesives have been conducted widely. The nano-composite material is a nano-particle containing composite material, modified by the nanometer material, in which the resin, rubber, ceramics, metal and other matrices are taken as the continuous phase, while the metal, semi-conductor, rigid particles, inorganic particles and other modifiers are taken as the disperse phase, prepared through dispersing the nanometer particles evenly into the matrix material. The nano-composite material has excellent properties that could not be matched by the general engineering materials, due to its features such as the nano-scaled small size effect in the disperse phase and the large specific surface area. Therefore, the nano-composite material is a new topic, which has a very broad application prospect and a promising commercial development future, and the modification of epoxy resin adhesive with the nano-materials has become one of the most popular research topics in the adhesive industry.

\section{Acknowledgements}

The study was supported by Sichuan Provincial Department of Education Project (182505); Teaching Teacher Support Program (DC1900007267) and Research Project of Chunhui Project of the Ministry of Education of the People's Republic of China (192641).

\section{References}

[1] Shao XF, Liu W, Li Y, Chaudhry, HR, Yue XG. Multistage implementation framework for smart supply chain management under industry 4.0. Technological Forecasting Social Change. 2021;162:120354. DOI: 10.1016/j.techfore.2020.120354.

[2] Fa D, Li Y, Li W, Yue XG, Boustras G. Weaving public health and safety nets to respond the COVID-19 pandemic. Safety Sci. 2021;134:105058. DOI: 10.1016/j.ssci.2020.105058.

[3] Malferrari S, Monaco C, Scotti R. Clinical evaluation of teeth restored with quartz fiber-reinforced epoxy resin posts. Int J Prosthodontics. 2003;16(1):39-44. DOI: 10.1007/s00384-002-0438-z.

[4] Jiang S, Lu C, Zhang S, Lu X, Tsai, SB, Wang CK, et al. Prediction of ecological pressure on resource-based cities based on an RBF neural network optimized by an improved ABC algorithm. IEEE Access. 2019;7:47423-36. DOI: 10.1109/ACCESS.2019.2908662.

[5] Jiang X, Lin A, Ma H, Li X, Li Y. Minimizing the thermal bridge through the columns in a refrigeration room. Appl Therm Eng. 2019;165:114565. DOI: 10.1016/j.applthermaleng.2019.114565.

[6] Huang G, Zhang X, Yin GZ, Guo H, Xiong YT. Development and application of microscopic observation device for multifield coupling of coal containing gas. Rock Soil Mechanics. 2015;36.715-21. DOI: 10.16285/j.rsm.2015.S2.102.

[7] Paul M, Lipic FS, Bates MA, Hillmyer MA. Nanostructured thermosets from self-assembled amphiphilic block copolymer/epoxy resin mixtures. J Am Chem Soc. 1998;120(35):8963-70. DOI: 10.1021/ja981544s.

[8] Gao D, Liu Y, Guo Z, Han J, Lin J, Fang H, et al. A study on optimization of CBM water drainage by well-test deconvolution in the early development stage. Water. 2018;10(7):929. DOI: 10.3390/w10070929.

[9] Ai F, Yin X, Hu R, Ma H, Liu W. Research into the super-absorbent polymers on agricultural water. Agr Water Manage. 2021:106513. DOI: 10.1016/j.agwat.2020.106513.

[10] Zhang X, Zang C, Ma H, Wang Z. Study on removing calcium carbonate plug from near wellbore by high-power ultrasonic treatment. Ultrason Sonochem. 2020:104515. DOI: 10.1016/j.ultsonch.2019.03.006.

[11] Mo L, Sun W, Jiang S, Zhao X, Ma H, Liu B, et al. Removal of colloidal precipitation plugging with high-power ultrasound. Ultrason Sonochem. 2020;(69):105259. DOI: 10.1016/j.ultsonch.2020.105259.

[12] Liu W, Ma H, Walsh A. Advance in photonic crystal solar cells. Renew Sust Energy Rev. 2019;(116):109436. DOI: 10.1016/j.rser.2019.109436.

[13] Ma H, Zhang X, Ju F, Tsai SB. A study on curing kinetics of nano-phase modified epoxy resin. Sci Rep. 2018;(8):3045. DOI: 10.1038/s41598-018-21208-0. 
[14] Ma H, Tsai SB. Design of research on performance of a new iridium coordination compound for the detection of $\mathrm{Hg}^{2+}$. Int J Environ Res Public Health. 2017;14(10):1232. DOI: 10.3390/ijerph14101232.

[15] Maggana C, Pissis P. Water sorption and diffusion studies in an epoxy resin system. J Polym Sci Part B: Polym Phys. 1999;37(11):1165-82. DOI: 10.1002/(SICI)1099-0488(19990601)37:11<1165::AID-POLB11>3.0.CO;2-E.

[16] Ho TH, Wang CS. Modification of epoxy resin with siloxane containing phenol aralkyl epoxy resin for electronic encapsulation application. Eur Polym J. 2001;37(2):267-74. DOI: 10.1016/S0014-3057(00)00115-4.

[17] Ratna D, Becker O, Krishnamurthy R, Simon GP, Varley RJ. Nanocomposites based on a combination of epoxy resin, hyperbranched epoxy and a layered silicate. Polymer. 2003;44(24):7449-57. DOI: 10.1016/j.polymer.2003.08.035.

[18] George GA, Cole-Clarke P, John N, Friend G. Real-time monitoring of the cure reaction of a TGDDM/DDS epoxy resin using fiber optic FT-IR. J Appl Polym Sci. 1991;42(3):643-57. DOI: 10.1002/app.1991.070420310. 